\title{
Effect of Process Parameters on Cutting Rate in WEDM of Incoloy 825
}

\author{
Mahesh $^{1}$, Dinesh Khanduja ${ }^{2}$, Vikas Kumar ${ }^{3}$, Rajeev Rathi ${ }^{4}$ \\ 1,2,3,4 (Mechanical Engineering, NIT Kurukshetra, India)
}

\begin{abstract}
Incoloy 825 is a super alloyof nickel iron and chromium widely used for heat and corrosion resistant applications. Due to its ultimate chemical properties, it is difficult to machine by conventional machine tools. In this present work, Incoloy 825 has been machined with the help of WEDM. WEDM is an unconventional machine tool used to machine high strength materials with high degree of accuracy. This paper presents an investigation on the optimization of machining parameters in WEDM of Incoloy 825. The main objective of this paper is to find the optimum cutting parameters to achieve high value of cutting rate. The cutting parameters considered in this study are pulse-on-time, pulse-off-time, peak current \& servo voltage. The setting of cutting parameters is determined by using Taguchi's L9 orthogonal array signal to noise ratio \& analysis of variance (ANOVA) were used to analyze the effect of parameters on cutting rate and identify the optimum cutting parameters. The research revealed that the significant factors were pulse-on-time \& pulse-offtime for cutting rate. The input parameter peak current was found to be insignificant in the study.
\end{abstract}

Keywords-WEDM, ANOVA, Pulse On Time, Pulse Off Time, Cutting Rate

\section{INTRODUCTION}

Recent developments in manufacturing industry have fuelled the demand for materials having higher strength, hardness and toughness. These materials pose a problem while machining with conventional machines available. The new materials available are lightweight combined with greater hardness and toughness. Sometimes their properties may create major challenges during their machining. The most generalized machine tool to machine these materials is WEDM.WEDM has evolved over time from being just used for manufacturing tools and dies to machining of exotic space-age alloys including Hastelloy, Inconel, titanium, Carbide, Polycrystalline diamond compacts and Conductive ceramics. Figure 1 shows the schematic of WEDM.

WEDM is a non-conventional, thermoelectric process which erodes the material by a series of discrete sparks between a work and tool electrode separated by a very thin film of dielectric fluid (deionised water). The dielectric is fed continuously to the machining zone to allow cooling action as well as to flush away the eroded particles. A very thin wire (generally $0.25 \mathrm{~mm}$ dia) under tension is used as tool. The wire is guided through a series of tensioning rollers. The wire does not touch the workpiece, so there is no physical force imparted on the workpiece compared to conventional machining processes. Therefore, the work holding forces are minimal in WEDM, preventing damage or distortion of workpiece.

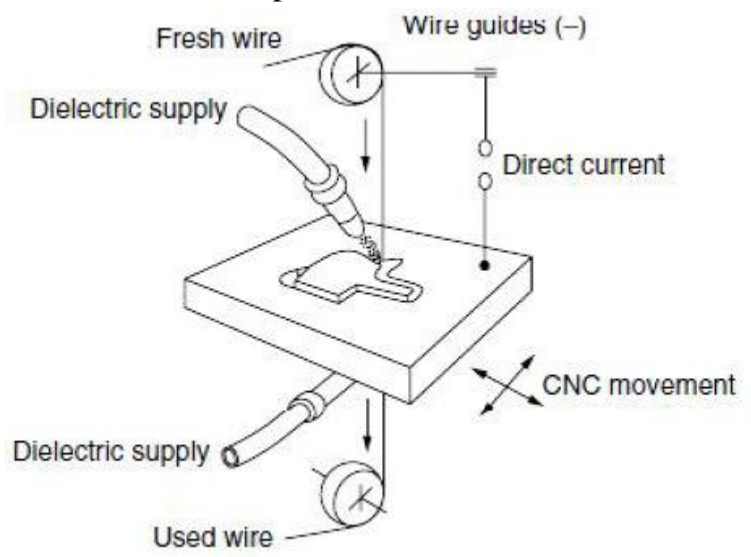

Fig. 1: Wire Electric Discharge Machining (WEDM)[2] 
The process leaves no residual burrs, so most of the components come out as finished ones and thus eliminating the need for any subsequent finishing operations. Sparks are formed through a sequence of rapid electrical pulses generated by the machine's power supply and these are thousands of times per second. Each spark forms an ionization channel under extremely high heat and pressure, in which particles flow between the wire electrode and the workpiece, resulting in vaporization of localized sections.[1]

\section{LITERATURE REVIEW}

Huang et al. In2003 carried out experiment investigation to determine the parameter setting during machining of SKD11 alloy steel by using the taguchi method (L18 mixed orthogonal array) \& Grey relational analysis. It was concluded that the table feed rate and pulse-on-time have significant influence on material removal rate, and pulse-on-time also has significant influence on surface roughness and gap width. In their prior investigation in 1997 using Taguchi method and non-linear regression analysis, they concluded that table feed and pulse-on-time have significant influence on the material removal rate, gap voltage and discharge frequency while gap width and surface roughness are mainly influenced by pulse-on-time.[3]

Mahapatra\&Patnaik in 2007 used Taguchi's L27 OA and non-linear regression analysis to design the experiment on various operating parameters,D2 tool steel was used as workpiece material and the response parameters were MRR, surface roughness and kerf width. The conclusion was that the discharge current, pulse duration, dielectric flow rate and the interaction between discharge current and pulse duration were more significant parameters for cutting operation.[4]

Tosun\&Cogun in 2003 in their investigation on AISI 4140 steel using regression analysis concluded that the wire wear ratio increases with increase in pulse duration and open circuit voltage while decreases with increase in wire speed and dielectric fluid pressure.[5]

Singh \&Gargin 2009 investigated the effect of various process parameters of WEDM like pulse-ontime, pulse-off-time, servo voltage, peak current, wire feed, and wire tension on hot die steel using one variable at a time approach. The optimal set of process parameters was predicted to maximize the MRR. It was noticed that the pulse on time and peak current had direct impact while pulse off time had indirect impact on MRR. Wire feed and wire tension had little effect on MRR.[6]

Harshdeep, Ishumongain 2015 used Taguchi L16 OA for investigating the effects of pulse on time, pulse off time, wire feed, wire tension \& peak current. They used this design for optimization of output parameters MRR, wire wear ratio \& surface roughness, they further applied multi response (signal to noise ratio) approach to measure the performance characteristics deviating from the actual value.[7]

\section{EXPERIMENTAL SETUP}

In the present work, experiments were carried out on electronic sprintcut 734 wire cut EDM machine tool in advanced manufacturing laboratory of the institute. The cutting rate of the machine was studied by varying at different settings, in the present work, only the electrical parameters namely pulse on time, pulse off time, peak current and servo voltage have been selected as variable parameters while parameters under the category of wire electrode, dielectric conditions and non electrical parameters have been kept fixed in experimentation. Taguchi L9 OA at 3 levels with 3 input parameters was selected for experimentation. Table 1 shows the various process parameters with their values at four different levels.

TABLE I: Process Parameters and levels

\begin{tabular}{|l|l|l|l|l|}
\hline PP & Factors & Level 1 & Level 2 & Level 3 \\
\hline Ton & A & 105 & 115 & 125 \\
\hline Toff & B & 35 & 45 & 55 \\
\hline IP & C & 120 & 140 & 160 \\
\hline
\end{tabular}

Selection of a particular OA is based on the number and levels of factors under study. Here, three parameters each at 3 levels have six degree of freedom (DOF), total DOF of OA should be greater than or equal to the total DOF required for experiment. The nearest possible OA satisfying the requirement is L9 OA. The "higher-the-better" quality characteristic has been used for calculating the signal to noise $(\mathrm{S} / \mathrm{N})$ ratio for cutting rate. $(\mathrm{S} / \mathrm{N})_{\mathrm{HB}}=-10 * \log \left(\square\left(1 / \mathrm{Y}^{2}\right) / \mathbf{n}\right.$ 


\section{EXPERIMENTAL RESULTS}

Nine experiments were conducted using Taguchi experimental design methodology and each experiment was simply repeated two times for obtaining $\mathrm{S} / \mathrm{N}$ values, in the present study all the designs, plots and analysis have been carried out using Minitab statistical software.

4.1 EXPERIMENTAL RESULTS FOR CUTTING RATE

The experimental values of cutting rate (raw data and $\mathrm{S} / \mathrm{N}$ ) are given in table 2

TABLE II: Experimental Data for Cutting Rate

\begin{tabular}{|l|l|l|l|l|l|}
\hline $\begin{array}{l}\text { Exp } \\
\text { No }\end{array}$ & $\begin{array}{l}\text { Factor A } \\
\text { Ton }\end{array}$ & $\begin{array}{l}\text { Factor B } \\
\text { Toff }\end{array}$ & $\begin{array}{l}\text { Factor C } \\
\text { IP }\end{array}$ & $\begin{array}{l}\text { Cutting rate } \\
(\mathbf{m m} / \mathbf{m i n})\end{array}$ & S/N ratio \\
\hline 1 & 105 & 35 & 120 & 1.563 & 3.8792 \\
\hline 2 & 105 & 45 & 140 & 0.889 & -1.0220 \\
\hline 3 & 105 & 55 & 160 & 0.440 & -7.1309 \\
\hline 4 & 115 & 35 & 140 & 1.976 & 5.9157 \\
\hline 5 & 115 & 45 & 160 & 1.134 & 1.0923 \\
\hline 6 & 115 & 55 & 120 & 1.334 & 2.5031 \\
\hline 7 & 125 & 35 & 160 & 3.078 & 9.7654 \\
\hline 8 & 125 & 45 & 120 & 3.240 & 10.2109 \\
\hline 9 & 125 & 55 & 140 & 2.650 & 8.4649 \\
\hline
\end{tabular}

\subsection{ANALYSIS AND DISCUSSION OF RESULTS}

Experiments were conducted by using the Taguchi approach to find out the effect of different parameters on the cutting rate. The average value of cutting rate and $\mathrm{S} / \mathrm{N}$ ratio for all levels of all factors has also been calculated. The main effects plots (raw data \& S/N ratio) are shown in Figure $2 \& 3$

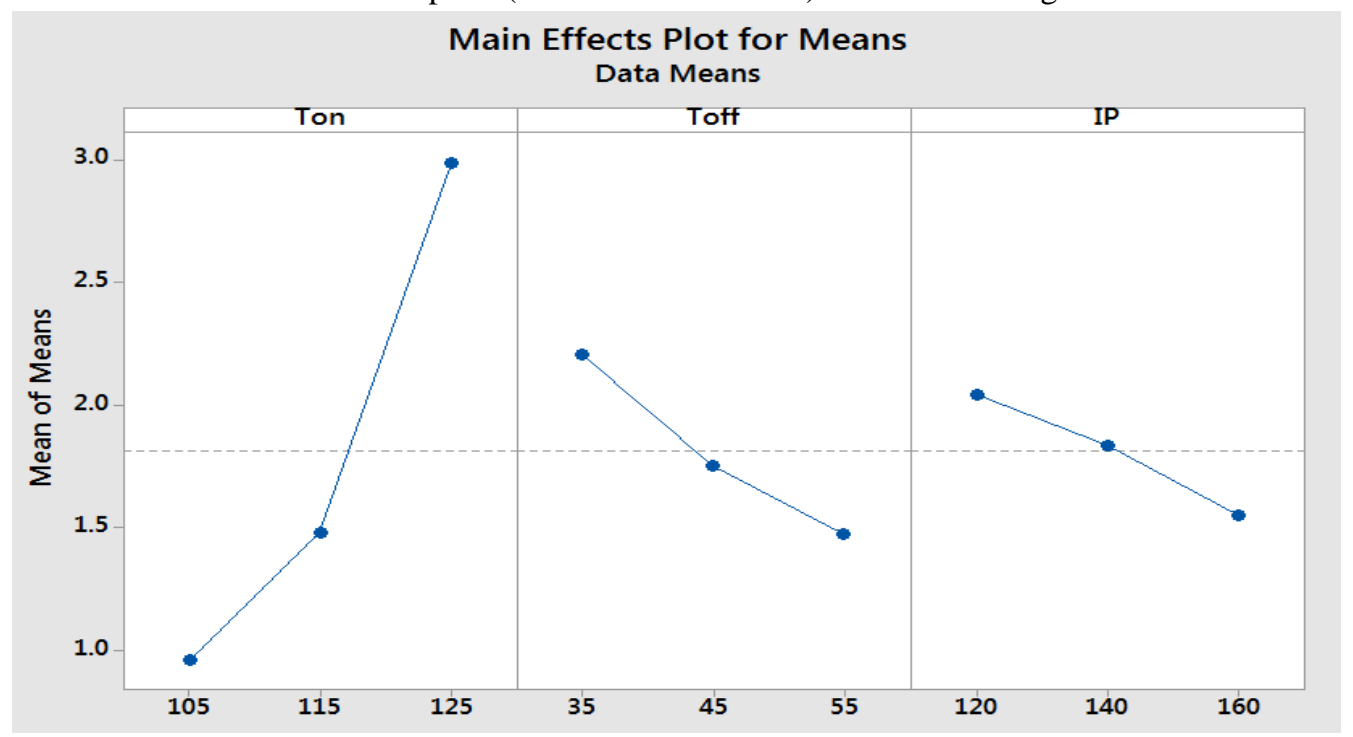

Fig. 2: Main Effects Plot for Cutting Rate

It is revealed from the Figure 2 that when pulse on time increases cutting rate also increases, this is attributed to the fact that discharge energy increases with increasing pulse on time leading to more cutting speed. But when pulse off time increases, cutting rate decreases. This is owing to the fact that time between two 
sparks increased with increasing pulse off time causing reduction in cutting rate. There is very little influence of peak current on cutting rate.

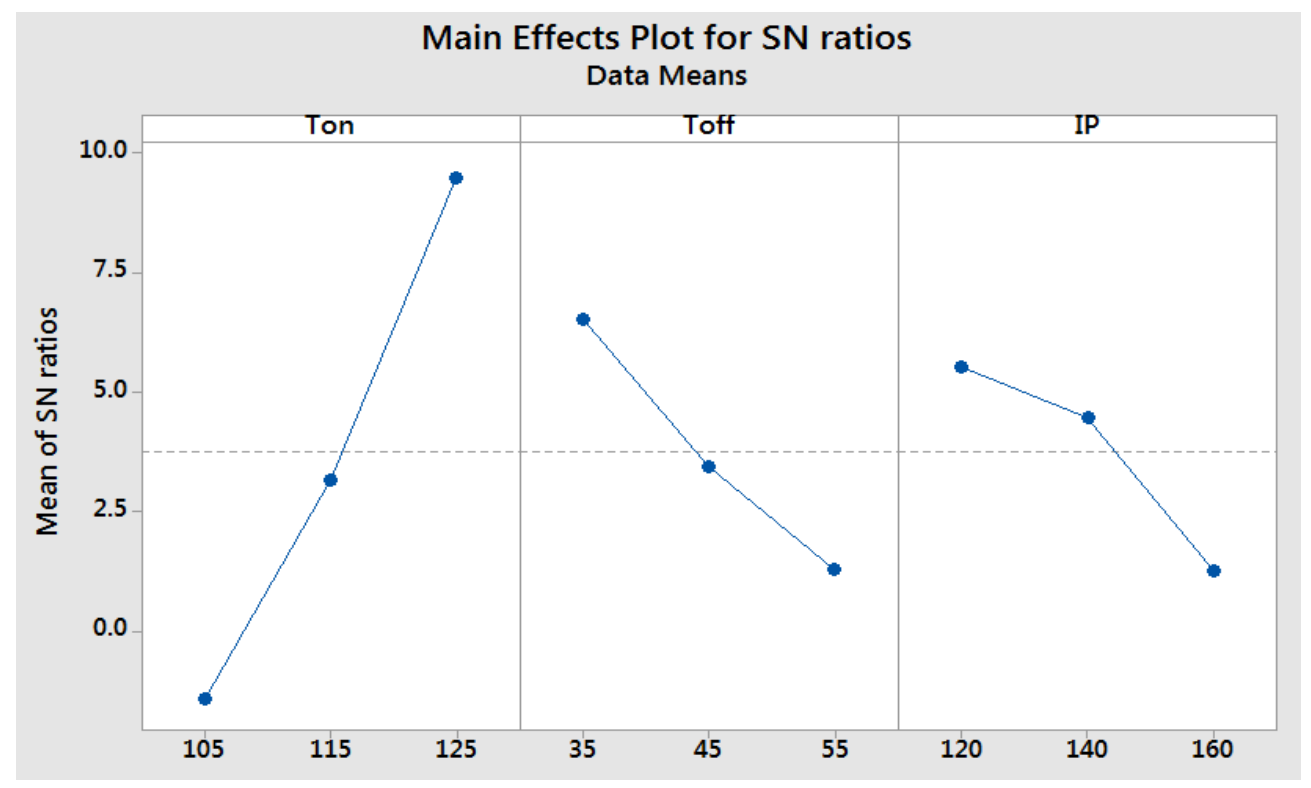

Fig. 3: Main Effects Plot for Cutting Rate (S/N data)

\subsection{ANALYSIS OF VARIANCE (ANOVA)}

The values obtained from the experiment are analysed using ANOVA technique. ANOVA is performed to determine the significant factors that are affecting the cutting rate. Table 3 shows the ANOVA table for raw data. ANOVA is performed to control the process variation and to categorize parameters into significant and insignificant ones. In the present investigation $90 \%$ confidence level is taken.

Table 3: ANOVA table for raw data

\begin{tabular}{|l|l|l|l|l|l|}
\hline Source & DOF & SS & V & F ratio & P\% \\
\hline Ton & 2 & 6.6436 & 3.3218 & 267.38 & 84.58 \\
\hline Toff & 2 & 0.8162 & 0.4081 & 32.85 & 10.39 \\
\hline IP & 2 & 0.3707 & 0.1853 & 14.92 & 4.71 \\
\hline Error & 2 & 0.0248 & 0.0124 & & 0.351 \\
\hline Total & 8 & 7.8555 & & & 100 \\
\hline
\end{tabular}

DOF: Degree Of Freedom, SS: Sum Of Squares, V: Variance, P\%: Percentage Contribution

As the cutting rate is "Higher is Better" type of characteristics, it is clear from Fig $2 \& 3$ that third level of pulse on time (A3) and first level of pulse off time (B1) result in maximum cutting rate.

TABLE IV. ANOVA table for S/N data

\begin{tabular}{|l|l|l|l|l|l|}
\hline Source & DOF & SS & V & F ratio & P\% \\
\hline Ton & 2 & 179.848 & 89.924 & 54.72 & 70.62 \\
\hline Toff & 2 & 41.650 & 20.825 & 12.67 & 16.35 \\
\hline IP & 2 & 29.865 & 14.932 & 9.09 & 11.72 \\
\hline Error & 2 & 3.287 & 3.287 & & 1.29 \\
\hline Total & 8 & 254.650 & & & 100 \\
\hline
\end{tabular}




\section{CONCLUSION}

In the present analysis, the effect of pulse-on time, pulse-off time and peak current was investigated in machining of Incoloy 825. Taguchi's L9 OA is used to design the experiment while ANOVA and S/N Ratio are used for optimization of result. Based on the experiments, following conclusions can be drawn from the research work:

1. The pulse on time and pulse off time have significant effect on cutting rate.

2. The pulse on time has $84.58 \%$ contribution while pulse off time has $10.39 \%$ contribution in controlling cutting rate as given in ANOVA for raw data.

3. As pulse on time increases or pulse off time decreases, cutting rate is increased. The peak current has little effect on cutting rate.

4. Pulse on time has $70.62 \%$ contribution while pulse off time has $16.35 \%$ contribution on cutting rates revealed in the $\mathrm{S} / \mathrm{N}$ ratio analysis.

5. Pulse on time and pulse off time are significant in both the ANOVA as, hence affect the mean value and variance around the mean of cutting rate.

\section{REFERENCES}

[1] AmiteshGoswami, Jatinder Kumar "Investigation of surface integrity, material removal rate and wire wear ratio for WEDM of

[2] Nimonic 80A alloy using GRA and Taguchi method" engineering science and technology, an international journal 17(2014)pp.173184.

[3] EI-HofyHassan, Advanced machining processes, McGraw-Hill publishing company limited, New York, USA, 2003.

[4] J.T Huang, Y.S Liao "optimization of machining parameters of wire -edm based on grey relational and statistical analysis" int.j.prod res 41(8)(2003)pp 1707-1720.

[5] S.S. Mahapatra, A.Patnaik. “optimization of wedm process parameters using taguchi method" int.J.adv.manuf.technol. 34(2007) pp 911-925.

[6] N. Tosum, C.Cogun "An investigation on wire wear in wedm" J.Mater process. Technol, 134(2003)pp 273-278

[7] Hari Singh, RohitGarg "effects of process parameters on MRR in WEDM" Journalof Achievements in materials and manufacturing engineering 32(2009)pp70-74.

[8] Harshdeep, Ishumonga "study of various performance parameters of wedm for H11 using taguchi L16 array" international journal for research in applied science and engineering technology(IJRASET)3(III)(2015)pp884-888.

[9] E.Atzemi et al. "surface and sub surface evaluation in coated wedm of inconel alloy 718"CIRP 33(2015) 389-394.

[10] Priyaranjan Sharma et al. "evaluation of wedm performance characteristics of inconel 706 for turbine disk application" materials and design 88(2015) 558-566.

[11] Muthu Kumar N et al "optimization of the wedm parameters on machining Incoloy 800 super alloy with multiple quality characteristics" international journal of engineering science and technology vol 2(6) 2010,1538-1547. 